\title{
Study of the possible allelopatic effects of Senecio inaequidens, $c$ (seneçon du cap)
}

Keywords: Senecio inaequidens, Allelopathy

\section{Introduction}

Senecio inaequidens, (seneçon du cap) is a plant native to South Africa, ${ }^{1}$ which was observed in France in 1936, after which a second source of infestation was identified in the vicinity of the tanneries of Mazamet. ${ }^{2,3}$ Being the fleeces of wool (toisons lainières) that transport the seeds of this plant, and it is there that since 1940, this plant began to spread throughout France, always in the vicinity of the wool industry. Likewise, this plant is currently located in other European countries such as Switzerland, Spain, Italy, Germany, Denmark, Holland. ${ }^{4}$ At the moment it is a weed that is in full expansion in Europe, and that can get to cover more than $90 \%$ of the infested surfaces. It is for these reasons that we intend to carry out this study, to know if one of the causes of its rapid expansion is due to exerting an exclusion pressure on other plant species, due to allelopathic effects. It is also a plant that predominates in prairie areas, and in areas not cultivated its dominance has also been observed so it is supposed to have allelopathic effects and for that reason it manages to develop more easily and cover those areas of new infestation. This is because there are many reports..$^{5-11}$ on the production of alkaloids, by the species of the genus Senecio, which cause harmful effects to the animals that consume them, so perhaps some allelopathic effects could also be expected towards other species of plants of the native flora It is also important to note that another possible cause of its large expansion in prairie areas, ${ }^{12,13}$ is because livestock (cows, sheep, horses, etc.), do not eat this plant because it produces substances that are toxic to animals, ${ }^{14,15}$ reason why, in the prairies this plant may predominate more, since animals do not consume it and with this its expansion is faster. In order to know if this plant presents those possible allelopathic effects, the following research work is proposed; posing as objectives: To evaluate the germination of different species of botanical families of plants, using the radical exudates and maceration juices of fresh aerial parts, to know if there are allelopathic effects, that can inhibit the germination and growth of the seedlings, in the first stages of development.

\section{Materials and methods}

Ist phase: reproduction of Senecio inaequidens plants for the production of radical exudates

To start the work on the possible allelopathic effects, plant material (cuttings) was collected on October 13.2000, which were put to root in the substrate, (neuhaus N2, content: dry matter mass of dry product $=25 \%$, organic matter $=20 \%, \mathrm{pH}$ water $=6.0$, resistivity $=800$ ohm-cm water retention capacity $=800 \mathrm{ml} / \mathrm{l}$ ) where they were kept, from the sowing of the cuttings to reproduce the plants that would serve as donators of the radical exudates. ${ }^{16,17}$ On November 18 the sand that would serve as a substrate was placed on the trays, where the seneçon du cap plants would grow, and distilled water was added during a period of 24 hours, this water was later removed and planting started of seedlings of Seneçon du cap, for the production of radical exudates.

Before transplanting the seedlings of Seneçon du cap to the trays, the roots were washed with distilled water, until all the residues of
Volume 3 Issue 3 - 2019

\author{
Medina MJA, J Maillet, P Marnott E, Ruiz NRE, \\ Coutiño RRR, Araujo GJG \\ Facultad de Ciencias Agronómicas, Universidad Autónoma de \\ Chiapas, México
}

\begin{abstract}
Correspondence: José Alfredo Medina Universidad Autónoma de Chiapas, Facultad de Ciencias Agronómicas. Carretera Ocozocoautla-Villaflores, km 80,Villaflores, Chiapas, México, CP 30460,Email jmedina_2157@hotmail.com
\end{abstract}

Received: April 30, 2018 | Published: May 10, 2019

the substrate where they grew were removed. Later the plants were transplanted in the trays. On November 20, the seedlings were implanted in the trays, (30 days after the cuttings were planted), and from that date, they were kept only with distilled water during the following three days, to facilitate their adaptation to the new substrate.

After the first three days of the transplant, the Hoagland nutrient solution was applied to the concentration of $0.25,{ }^{18}$ for a period of four days, with the purpose of adapting to it. After the first four days that were maintained with the Hoagland solution at the concentration of 0.25 , they were already maintained during the entire time they took growth with the nutrient solution at the concentration of 0.50 , until the end of the experiment, as recommended by (López \& Maillet, personal communication).

From the moment of the transplant, each day $200 \mathrm{ml}$ of the nutritive solution of Hoagland was added to each tray to maintain the plants, this amount of solution increased as the plants grew. Thus, upon reaching 30 days of the transplant, they were increased to $300 \mathrm{ml}$ of nutrient solution daily, and after 60 days, it was again increased to 500 $\mathrm{ml}$ of nutrient solution per day, until 90 days, when they were finally added $800 \mathrm{ml}$ of the nutritive solution per day, to maintain them.

On November 27 all the plants were pruned to obtain a similar development. And on November 30 and December 7, fungicidal treatments were given with the M45 captan product, which contains $80 \%$ mancozeb at the dose of $2 \mathrm{gr}$ of product/liter of water, to control rust (Puccinia lagenophorae), which It was presented in the plants. The trays where the plants grew, have the following measures: height $16.0 \mathrm{~cm}$ x $53.5 \mathrm{~cm}$ long and $34.5 \mathrm{~cm}$ wide. Planting 24 plants per tray, distributed in three rows with a separation of $10 \mathrm{~cm}$, to have a population density of $130 / \mathrm{m}^{2}$.

The conditions of temperature and luminosity in which the plants were kept in the greenhouse were the following: 15 light hours, distributed as follows, from 6 to 9 in the morning and from 16 to 21 hours, with temperatures of $2{ }^{\circ} \mathrm{C}$ during the day and $20^{\circ} \mathrm{C}$ during the night. The lighting in the greenhouse was with Bartholin type bulbs $0.5 \mathrm{~J}-20^{\circ}<\mathrm{T}<+40^{\circ}$ ) and high pressure sodium tubular steam lamps of the SONT Agro type, with an energy yield of $300 \mathrm{~mW} / \mathrm{W}$ 


\section{2nd phase: experimentation with radical exudates}

The experiments were carried out in the Laboratory of Biology and Pathology Végétales, of the Ecole Nationale Superieure Agronomique de Montpellier, France; using seven representative species of equal number of families, and the seneçon de cup, the species are listed below: Senecio inaequidens D.C. (Seneçon du cap) Asteraceae; Lycopersicum esculentum L. cv. Saint Pierre (Tomato) Solanaceae; Daucus carota L. cv. From Colmar to couer rouge (Carrot) Umbelliférae; Raphanus sativus L. cv. Flamboyant (Radis) Cruciferae; Hordeum vulgare L. cv. Alpha (Barley) Gramineae/Poaceae; Lactuca sativa L. cv. Rouge Grenobloise (Lettuce) Compositae; Bromus catharticus (Brome catarthiques) Gramineae /Poaceae; Medicago sativa L. cv. Salernes (Luzerne) Papilionaceae.

Three experiments were carried out with radical exudates in three different phonological stages of development of the seneçon du cap (juvenile, intermediate and flowering), and the same nutrient solution of Hoagland was used as controls, with which the seneçon du cap plants were maintained. Distilled water, to observe the germination of the seeds and the growth of the hypocotyl. In each treatment, 50 seeds of each species were used to observe and evaluate the possible allelopathic effects of the seneçon du cap. In all the trials (radical exudates), the observation period for seed germination was seven days, with daily counts of the number of seeds germinating each day, at the end of which the hypocotyl was measured the seedlings. The measurement of the seedlings was carried out in the following way, from the point where the root formation begins until the beginning of the formation of the first leaf, and for the case of the barley, it was measured in the same way, from the point of formation of the roots, but the whole seedling, because of the difficulty of measuring the point where the first leaf leaves Finally, to start all the allelopathy trials on December 12, when the seneçon du cap plants had 22 days of being transplanted to the trays, $100 \mathrm{ml}$ of the nutrient solution was collected with the radical exudates of each tray for the realization of the first test. At the time of the first trial, the plants of Seneçon du cap, presented on average the following plant heights by trays: (1) $27.91 \mathrm{~cm}$. (2) $27.5 \mathrm{~cm}$. (3) $26.08 \mathrm{~cm}$. and (4) $28.95 \mathrm{~cm}$. The first trial (juvenile phonological stage) began on December 13, 2000, concluding on the 21 st of the same month. To carry out the second trial (intermediate phenological stage), $100 \mathrm{ml}$ of the nutritive solution was collected on a daily basis on January 4 and 5, 2001, and the solution collected on January 4 was kept refrigerated. Together with the solution collected on January 5, $800 \mathrm{ml}$ of solution were mixed to obtain the amount required for the test. It should be noted that at this time the seneçon du cap plants had 45 days of being transplanted to the trays The third test with the radical exudates (phonological stage of flowering) was carried out from March 30, 2001, obtaining in the same way to the previous test, the amount of $800 \mathrm{ml}$ of the nutrient solution with the radical exudates. By this time the plant had 130 days of being transplanted to the trays and was in the flowering stage.

It is important to note that there were some differences in the performance of the different tests, being fundamentally the following: In the case of the first test with radical exudates, circular petri dishes, $10 \mathrm{~cm}$ in diameterx $1.1 \mathrm{~cm}$ high, were used, and three white filter papers of type MN40 $\mathrm{m}$ of $9 \mathrm{~cm} \varnothing$ were placed in the base (plates of ashless filters, white boxes) (Macherey-nagel), and on the paper the 50 seeds were placed, to which they were added on a single occasion, $8 \mathrm{ml}$ of the solution of each treatment, to each Petri dish. For tests 2 and 3 with radical exudates, plastic boxes with the following dimensions were used: $12.0 \times 18.5 \times 15 \mathrm{~cm}$ in width, length and height and as a substrate they were placed accordion type filter paper. In each germination box, $50 \mathrm{ml}$ of the treatment solution (distilled water, nutrient solution or radical exudates) were added on one occasion, placing seeds of two species per box, that is, 100 seeds per box.

\section{Experimental design}

The experimental design used to implant the tests with the radical exudates and maceration juices, in the germination of seeds and the growth of hypocotyl, was a factorial arrangement of $8 \times 3$, in divided plots, placed in a completely block design. randomized, with three repetitions; where the factors were the Species (8) and Solutions (3), the main plots being the Solutions factor (distilled water, nutrient solution and radical exudates) and the Species factor, (Senecio inaequidens DC, Lycopersicum esculentum L. Daucus carota L., Raphanus sativus L., Hordeum vulgare L., Lactuca sativa L., Bromus catharticus, Medicago sativa L.), subplots.

\section{Statistic analysis}

The analysis of variance was performed, for the parameters evaluated, which were $n^{\circ}$ of germinated plants, height of the hypocotyl, germination index, ${ }^{5}$ the latter, to observe if there were differences between the treatments of the solutions and a acceleration or delay in germination. Finally, the hypocotyl growth of the plants was compared in the different Solutions treatments, from the tests with the radical exudates.

\section{Results and discussion}

\section{First trial with radical exudates}

As a result of the first trial (juvenile phonological stage) that was carried out as of December 13, 2000, and which was concluded on the 21 st of the same month. with the radical exudates of seneçon du cap, for the variable germination of seeds, it was possible to verify according to the results of the analysis of variance (Table 1), that only statistical differences were observed for the Species factor, a result that can be considered normal, since that, as expected, there are differences in germination between different plant species (Table 2). However, no statistical differences were observed for the Solutions factor, which is where it would be interesting to observe the behavior of the germination of the different species, depending on the solutions used for germination (Table 1). It is also important to note that no statistical differences were observed for the Interaction factor (Species $\mathrm{x}$ Solutions), which shows that, at this phonological stage, the seneçon du cap plant has no allelopathic effect on the germination of any of the species used to evaluate these possible effects (Table 1).

Table I Variance analysis of seed germination with the treatment of radical exudates in the Ist. phenological stage of the plants of seneçon du cap. (Ist trial)

\begin{tabular}{llllll}
\hline & S.c.e. & Ddl & S. means & Test $\mathbf{f}$ & Prob ab \\
\hline Var. total & 98.97 & 80 & 1.24 & & \\
V. especie & 77 & 8 & 9.70 & 32.43 & 0.0000 \\
V. solution & 1.55 & 2 & 0.77 & 2.59 & 0.0828 \\
V.interacc & 3.68 & 16 & 0.23 & 0.77 & 0.7122 \\
V. residual & 16.15 & 54 & 0.30 & & \\
\hline
\end{tabular}

When performing the analysis of variance of the measurement of the size or height of the hypocotyl, of the results obtained seven days after the first trial where the possible allelopathic effects of the 
senecon du cap are being evaluated, it was observed that there were only statistical differences for the factor Species, that is to say, as a consequence of the differences between the species, the growth of the hypocotyl is greater in some species than in others, but not as results of the effect of the radical exudates of the seneçon du cap; This is because no statistical differences were observed for the factors Solutions and Interactions (Species x Solutions) (Table 3). Second trial with radical exudates: When performing the statistical analyzes of the results obtained on the germination of the seeds in this test, it was observed that there were statistical differences for all the factors (Species, Solutions and Interactions) (Table 4).

Table 2 Comparison of Tukey's multiple range test, seed germination with treatment of radical exudates (juvenile phonological stage) of seneçon du cap plants. (Ist trial)

\begin{tabular}{|c|c|c|c|}
\hline Especie & Meanș & Groups & \\
\hline Barley & 48.33 & $A$ & \\
\hline Medicago-salernes & 46.22 & A & \\
\hline Lettuce & 46.22 & A & \\
\hline Radish & 42.22 & B & \\
\hline Carrot & 41.22 & B & \\
\hline Brome cathartiques & 35.00 & $c$ & \\
\hline Medicago-mauguio & 30.22 & & $\mathrm{D}$ \\
\hline Madicago-ampus & 26.67 & & D \\
\hline Seneçon du cap & 23.11 & & $E$ \\
\hline
\end{tabular}

Table 3 Analysis of variance of stem height of germinated seedlings with the treatment of radical exudates in the Ist. phenological stage of the plants of seneçon du cap. (Ist trial)

\begin{tabular}{llllll}
\hline & S.c.e. & Ddl & S. means & Test f & Prob ab \\
\hline Var. total & 6519.95 & 80 & 81.50 & & \\
V. especie & 5677.28 & 8 & 709.66 & 66.15 & 0.0000 \\
V. solution & 55.88 & 2 & 27.94 & 2.60 & 0.0814 \\
V.interacc & 207.46 & 16 & 12.97 & 1.21 & 0.2918 \\
V. residual & 579.33 & 54 & 10.73 & &
\end{tabular}

Table 4 Analysis of variance of seed germination with the treatment of radical exudates in the 2 nd phenological stage of seneçon du cap (2nd essay)

\begin{tabular}{llllll}
\hline & S.c.e. & Ddl & S. means & Test f & Probab \\
\hline Var. total & 6687.78 & $7 \mathrm{I}$ & 94.19 & & \\
V. especie & 5420.22 & 7 & 774.32 & $46.8 \mathrm{I}$ & 0.0000 \\
V. solution & 100.03 & 2 & 50.01 & 3.02 & 0.0566 \\
V.interacc & 373.53 & 14 & 26.68 & $1.6 \mathrm{I}$ & 0.1096 \\
V. residual & 794.00 & 48 & 16.54 & & \\
\hline
\end{tabular}

The statistical significance of the Species factor (Table 5), shows that there are differences in the germination of the different species, however, this is to be expected, because each species can have a higher or lower percentage of germination, typical of its species, but perhaps not due to the effects of radical exudates, which will need to be confirmed in the interactions of the Species and Solutions factors. However, it was observed that barley was the species with the highest germination and Seneçon du cap, which presented the lowest germination, but statistically different. The results of the measurement of the hypocotyl size of the evaluated species showed statistical differences in the three factors (Species, Solutions and Interactions), as shown in Table 6 .

Table 5 Comparison of Tukey's multiple range test, seed germination with the treatment of radical exudates (intermediate phenological stage) of seneçon du cap plants. (2nd essay)

\begin{tabular}{lllllll}
\hline Especie & Means & Groups & & \\
\hline Barley & 49.22 & A & & & & \\
Lettuce & 47.56 & A & B & & & \\
Carrot & 45.44 & A & B & & & \\
Radish & 44.22 & & B & & & \\
Tomato & 43.44 & & B & C & & \\
Brome cathartiques & 40.44 & & & C & D & \\
Medicago-salernes & 37.22 & & & & D & \\
Madicago-ampus & 26.67 & & & & D & \\
Seneçon du cap & 20.00 & & & & & E \\
\hline
\end{tabular}

Treatments with the same letter are statistically the same

Table 6 Analysis of variance of the height of the stem of the germinated seedlings with the treatment of radical exudates in the 2 nd phenological stage of the plants of seneçon du cap (2nd essay)

\begin{tabular}{llllll}
\hline & S.c.e. & Ddl & S. means & Test f & Probab \\
\hline Var. total & 758.27 & $7 \mathrm{I}$ & 10.62 & & \\
V. espècie & 719.16 & 7 & 102.74 & $388.7 \mathrm{I}$ & 0.0000 \\
V. solution & 18.44 & 2 & 9.22 & 34.89 & 0.0000 \\
V.interacc & 7.97 & 14 & 0.57 & 2.15 & 0.0248 \\
V. residual & 12.69 & 48 & 0.26 & & \\
\hline
\end{tabular}

However, the tendency observed when carrying out Tukey's multiple range tests (Table 7) is the same observed in germination, that is, that some plants have a larger hypocotyl size, due to the characteristics of the species, and perhaps not because of the effects of the radical exudates, in this sense, it is also observed that the barley, presented the largest plant size, while Carrot, Senecon du cap and Medicago-salernes, presented the smaller size of hypocotyl.

Table 7 Comparison of Tukey's multiple range test, seed germination with treatment of radical exudates (intermediate phenological stage) of seneçon du cap plants. (2nd trial)

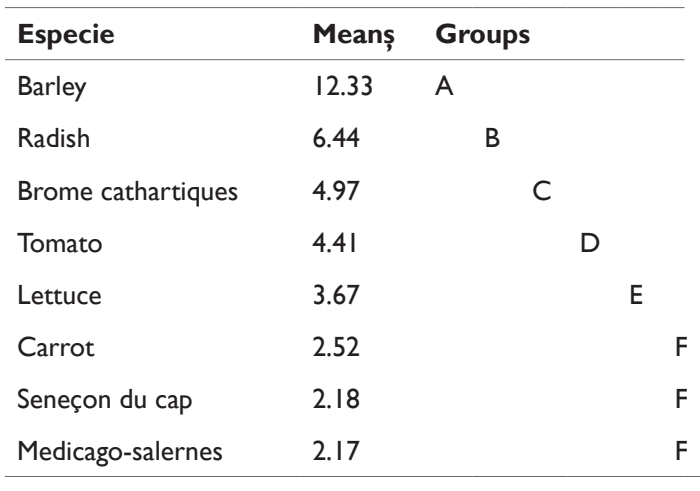

Treatments with the same letter are statistically the same 
In the results obtained, on the effects of the Solutions, in the behaviour of the hypocotyl size of the species, it was observed in the analysis of variance that there are statistical differences for this factor (Table 8), where it is observed that the solution nutritive, favored a greater growth of the hypocotyl of all the plants, secondly the solution that contains the radical exudates, but statistically different from the first one, and of the distilled water, which was the least hypocotyl size presented by the plants. These results may indicate that the plants that grew in the solution containing the radical exudates, had a lower nutrient disposal, because the plants of Seneçon du cap, have extracted them from the nutrient solution and this has arrived with less nutrients, than the control nutrient solution and for the specific case of distilled water, it could be considered normal for plants that have a smaller hypocotyl size, mainly because they have grown only with water and without any nutritional supplement, compared with the two solutions previous, especially for the contents of nutrients of the same (Table 8A).

Table 8A Results of the multiple range comparison tests of the solutions used, with the height of the stem of the germinated seedlings with the treatment of radical exudates in the 2 nd phenological stage of the plants of seneçon du cap. (2nd essay)

\begin{tabular}{lllll}
\hline Solutions & Means & \multicolumn{2}{c}{ Groups } \\
\hline Nutritious solution & 5.40 & A & & \\
Radical exudates & 4.93 & & B \\
Distilled water & 4.17 & & & C \\
\hline
\end{tabular}

Treatments with the same letter are statistically the same

\section{Factor solutions}

\section{Factor interactions}

Species x Solutions Finally, when observing in detail the behavior of the statistical analyzes, and the multiple range tests, of the Interactions, it can be verified that the behavior of the Species, with the Solutions, if there are statistical differences, but not by the effect of the exudates radicals, but plants grew less with distilled water or more with the nutritive solution, but in any case statistically equal to the treatment with radical exudates, as can be seen in the detailed grouping by species and solutions presented below (Table 8B).

Table 8B Detailed grouping by species and solutions presented below

\begin{tabular}{llllll}
\hline Barley & Meanș & \multicolumn{2}{l}{ Groups } \\
Nutritious solution & 13.0 & A & \\
Radical exudates & 12.4 & A & & \\
Distilled water & II.53 & & B & \\
\hline & & & & \\
\hline Radish & Meanș & Groups \\
Nutritious solution & 7.80 & C & & \\
Radical exudates & 6.3 & & D & E \\
Distilled water & 5.1 & & & E \\
\hline & & & & \\
\hline Tomato & Meanș & Groups \\
Nutritious solution & 5.47 & E & & \\
Radical exudates & 4.43 & E & F & \\
Distilled water & 3.33 & & F & \\
\hline
\end{tabular}

\begin{tabular}{|c|c|c|c|}
\hline Brome cathartiques & Meanș & \multicolumn{2}{|c|}{ Groups } \\
\hline Nutritious solution & 5.40 & \multicolumn{2}{|l|}{$\mathrm{E}$} \\
\hline Radical exudates & 5.23 & \multicolumn{2}{|l|}{$E$} \\
\hline Distilled water & 4.27 & \multicolumn{2}{|l|}{$E$} \\
\hline Letucce & Meanș & \multicolumn{2}{|c|}{ Groups } \\
\hline Nutritious solution & 4.23 & \multicolumn{2}{|l|}{$\mathrm{F}$} \\
\hline Radical exudates & 3.70 & \multirow[t]{2}{*}{$\mathrm{F}$} & G \\
\hline Distilled water & 3.07 & & G \\
\hline Carrot & Meanș & \multicolumn{2}{|c|}{ Groups } \\
\hline Nutritious solution & 2.77 & G & $\mathrm{H}$ \\
\hline Radical exudates & 2.67 & \multirow[t]{2}{*}{ G } & $\mathrm{H}$ \\
\hline Distilled water & 2.13 & & $\mathrm{H}$ \\
\hline Seneçon du cap & Meanș & \multicolumn{2}{|c|}{ Groups } \\
\hline Nutritious solution & 2.37 & $\mathrm{H}$ & I \\
\hline Radical exudates & 2.27 & $\mathrm{H}$ & I \\
\hline Distilled water & 1.90 & & I \\
\hline Medicago & Meanș & \multicolumn{2}{|c|}{ Groups } \\
\hline Nutritious solution & 2.40 & \multicolumn{2}{|l|}{ I } \\
\hline Radical exudates & 2.10 & \multicolumn{2}{|l|}{ I } \\
\hline Distilled water & 2.0 & \multicolumn{2}{|l|}{ I } \\
\hline
\end{tabular}

\section{Third trial with radical exudates}

The results of the statistical analyzes carried out on the germination of the seeds of plants, which were subjected to the treatment of the radical exudates of the Seneçon du cap plant, in the so-called 3rd. phenological stage (flowering), showed the following results (Table 9), where it is observed that there are statistical differences for the factor Species, so it was proceeded to perform the corresponding multiple range tests, to determine the differences between treatments.

Table 9 Analysis of variance of seed germination with the treatment of radical exudates in the stage of flowering of the seneçon du cap (3rd trial)

\begin{tabular}{llllll}
\hline & S.c.e. & Ddl & S. means & Test f & Probab \\
\hline Var. totals & 7204.32 & $7 \mathrm{I}$ & 101.47 & & \\
V. especie & 5495.65 & 7 & 785.09 & 27.53 & 0.0000 \\
V. solution & 69.44 & 2 & 34.72 & 1.22 & 0.3054 \\
V.interacc & 273.89 & 14 & 19.56 & 0.69 & 0.7762 \\
V. blocks & 53.69 & 2 & 26.85 & 0.94 & 0.3996 \\
V. residual & 1311.64 & 46 & 28.51 & & \\
\hline
\end{tabular}

\section{Species factor}

The analysis of the multiple range test of Tukey, on the Species factor, shows the differences between them, where it can be observed (Table 10), that the species of Barley, Lettuce and Radish, were the ones that presented the highest quantities of seeds germinated and are statistically equal. On the contrary, the species that presented the lowest amounts of germinated seeds were Seneçon du cap and 
Medicago-salernes, which are statistically different from each other. However, it is believed that these differences between the species, in terms of the amounts of germinated seeds, is not due to the radical exudates of the Seneçon du cap, but rather to the characteristics of each species, since no differences were observed statistics on the factor called Interactions. The second parameter evaluated, which is the size of the hypocotyl, when performing the analysis of variance, presented the following results (Table 11), where the factors Species, Solutions and Interactions were observed, presented statistical significance, so they were practiced Tukey's multiple comparison test analyzes.

Table I 0 Comparison of Tukey's multiple range test, of seed germination with the treatment of radical exudates (phenological flowering stage) of seneçon du cap plants (3rd trial)

\begin{tabular}{llllll}
\hline Especie & Meanș & Groups & \\
\hline Barley & 49.78 & A & & \\
Lettuce & 47.56 & A & & \\
Radish & 47.44 & A & & \\
Brome cathatiqques & 40.67 & \multicolumn{2}{c}{ B } & & \\
Carrot & 40.56 & \multicolumn{2}{c}{ B } & & \\
Tomato & 39.33 & & B & & \\
Seneçon du cap & 32.44 & & \multicolumn{2}{c}{ C } & \\
Madicago-salernes & 21.44 & & & & D \\
\hline
\end{tabular}

Treatments with the same letter are statistically the same

Table I I Analysis of variance of the stem height of the germinated seedlings with the treatment of radical exudates in the flowering stage of the seneçon du cap (3rd trial)

\begin{tabular}{llllll}
\hline & S.c.e. & Ddl & S. means & Test f & Probab \\
Var. total & $\mathbf{8 0 2 . 0 2}$ & $\mathbf{7 I}$ & $\mathbf{I I} .30$ & & \\
\hline V. especie & $78 I .29$ & 7 & III.6I & 1549.54 & 0.0000 \\
V. solution & 9.19 & 2 & 4.60 & 63.82 & 0.0000 \\
V.interacc & 8.00 & 14 & 0.57 & 7.93 & 0.0000 \\
V. blocks & 0.23 & 2 & $0.1 \mathrm{I}$ & $\mathrm{I} .57$ & 0.2170 \\
V. residual & 3.31 & 46 & 0.07 & & \\
\hline
\end{tabular}

\section{Species factor}

Tukey's multiple range comparison analysis, between the different species, subjected to the treatment of the radical exudates of seneçon du cap, in the phenological stage of flowering, shows that the plants of Barley, Rabano, brome cathartiques and tomato, were the that presented greater hypocotyl sizes, in descending order, but all statistically different from each other. On the contrary, Cebada, Lechuga, seneçon du cap and Madicago-salernes, presented the smallest hypocotyl sizes and all are statistically equal to each other. In this case it will be important to observe the behavior of these results, in relation to the interaction they present with the factor Solutions, factors that also presented statistical differences (Table 12).

\section{Factor solutions}

When the analysis of Tukey's multiple range comparison test (Table 13A) was performed, to this factor, it was observed that the three solution levels are statistically different, that is, that the hypocotyls of the species grew differently in each type from solution.
However, it is important to note that the plants that germinated in the solution with the radical exudates were those that were larger and statistically different from the other two.

Table I 2 Comparison of Tukey's multiple range test, seed germination with the treatment of radical exudates (phenological stage of flowering) of seneçon du cap plants (3rd trial)

\begin{tabular}{|c|c|c|c|}
\hline Especie & Means & Groups & \\
\hline Barley & 12.34 & A & \\
\hline Radish & 4.32 & B & \\
\hline Brome cathartiques & 3.26 & $c$ & \\
\hline Tomato & 2.69 & & $\mathrm{D}$ \\
\hline Carrot & 2.28 & & $\mathrm{E}$ \\
\hline Lettuce & 2.27 & & $E$ \\
\hline Seneçon du cap & 2.02 & & $\mathrm{E}$ \\
\hline Medicago-salernes & 1.74 & & $E$ \\
\hline
\end{tabular}

Treatments with the same letter are statistically the same

On the contrary, the plants that grew in the distilled water solution were the ones with the smallest hypocotyl sizes.

By virtue of the above, it could be said that the radical exudates do not present any allelopathic effect, since it was precisely in that solution, where the plants grew the most.

\section{Factor interactions: species $\mathbf{x}$ solutions}

The detailed breakdown of Tukey's multiple range test, of the interactions between the species and the solutions, (all attached below), shows that the statistical differences observed in the analysis of variance, are due to the smaller size of the hypocotyl of the plants, when these germinated in distilled water, these results are very clear in the cases of the species of Barley, Radish and Tomato. On the contrary, the plants that germinated in the nutritive solutions and with the radical exudates, in these and the other species were statistically equal, this means that, in no case was a negative effect of the radical exudates observed in the growth of the hypocotyls of plants. That is, it does not cause any allelopathic effect in these plant species of these families, at least until the phenological stage of flowering (Table 13B). The analysis of variance of the results on the germination index of the seeds, during the seven days of the trial, show that there were only statistical differences for the factor Species (Table 14).

Table I3A Results of the multiple range comparison tests of the solutions used, with the height of the stem of the seedlings in the 3 rd phenological stage (flowering) of the plants of seneçon du cap (3rd trial)

\begin{tabular}{lllll}
\hline Solutions & Means & \multicolumn{2}{c}{ Gruops } \\
\hline Radical exudates & 4.20 & A & & \\
Nutritious solution & 4.03 & \multicolumn{2}{c}{ B } & \\
Distilled water & 3.37 & & & C \\
\hline
\end{tabular}

Treatments with the same letter are statistically the same.

When analyzing the results of Tukey's multiple range test (Table 15), on the germination indexes, it is observed that the species with the fastest germination were, Barley, lettuce and Rabano, besides being statistically equal. While tomato and seneçon du cap, were the species that are slowest to germinate, regardless of the solution treatment they 
receive. These results do not show that there have been effects on the part of the radical exudates in delaying the germination of any of the evaluated species.

Table I3B The detailed breakdown of Tukey's multiple range test, of the interactions between the species and the solutions

\begin{tabular}{|c|c|c|}
\hline Barley & Means & Groups \\
\hline Nutritiuos solution & & A \\
\hline Radical exsudates & & A \\
\hline Distilled water & & B \\
\hline Radish & Meanș & Groups \\
\hline Nutritiuos solution & & C \\
\hline Radical exudates & & C \\
\hline Distilled water & & D \\
\hline Tomato & Meanș & Groups \\
\hline Nutritiuos solution & & $\mathrm{E}$ \\
\hline Radical exudates & & $\mathrm{E}$ \\
\hline Distilled water & & G \\
\hline Brome cathartiques & Meanș & Groups \\
\hline Radical exudates & & $E$ \\
\hline Nutytious solution & & $E$ \\
\hline Distilled water & & E \\
\hline Lettuce & Meanș & Groups \\
\hline Radical exudates & & G \\
\hline Nutritious solution & & G \\
\hline Distilled water & & G \\
\hline Carrot & Meanș & Groups \\
\hline Nutritious solution & & G \\
\hline Radical exudates & & G \\
\hline Distilled water & & G \\
\hline Seneçon du cap & Meanș & Groups \\
\hline Radical exudates & & G \\
\hline Nutritiuos solution & & G \\
\hline Distilled water & & G \\
\hline Medicago-salernes & Meanș & Groups \\
\hline Nutritiuos solution & & $\mathrm{H}$ \\
\hline Radical exudates & & $\mathrm{H}$ \\
\hline Distilled water & & $\mathrm{H}$ \\
\hline
\end{tabular}

Table 14 Analysis of variance of germination index of germinated seeds with the treatment of radical exudates in the stage of flowering of plants of seneçon du cap (3rd trial)

\begin{tabular}{llllll}
\hline & S.c.e. & Ddl & S. means & Test f & Probab \\
\hline Var. total & 1039.73 & $7 \mathrm{I}$ & 14.64 & & \\
V. especie & 876.00 & 7 & 125.14 & 47.20 & 0.0000 \\
V. solution & 3.40 & 2 & 1.70 & 0.64 & 0.5361 \\
V. interacc & 33.05 & 14 & 2.36 & 0.89 & 0.5743 \\
V. blocks & 5.33 & 2 & 2.66 & $\mathrm{I}$ & 0.3758 \\
V. residual & 121.96 & 46 & 2.65 & & \\
\hline
\end{tabular}

Table 15 Comparison of Tukey's multiple-range test, of seed germination indexes with the treatment of radical exudates (phenological stage of flowering) of seneçon du cap plants (3rd trial)

\begin{tabular}{llllll}
\hline Especie & Means & Groups & \\
\hline Barley & 16.56 & A & & \\
Lettuce & 15.67 & A & & \\
Radish & 15.65 & A & & \\
Carrot & 12.19 & & B & & \\
Brome cathartiques & 11.52 & & B & & \\
Medicago-salernes & 9.52 & & & C & \\
Tomato & 8.17 & & & C & D \\
Seneçon du cap & 6.64 & & & & D \\
\hline
\end{tabular}

\section{Conclusion}

As a result of the research work carried out with the radical exudates of the seneçon du cap plant, in three phenological stages (juvenile, intermediate and flowering), it was found that at least for the species used in the experimentation, it did not cause them an allelopathic effect, in none of the evaluated parameters, germination, hypocotyl growth or stem height.

\section{Acknowledgments}

None.

\section{Conflicts of interest}

Authors declare that there is no conflict of interest.

\section{References}

1. Jäger EG. Möglichkeiten der prognose synanthroper pflanzenausbreiotungen. In Ernst. Invasion, dispersal and ecology of the south african neophyte Senecio inaequidens in the Netherlands. Acta Bot Neerl. 1988;47(1):131-151.

2. Michez JM. Le seneçon du cap, de la laine à la vigne. Phytoma. 1995;468:39-41.

3. Michez JM. Biologie et Ecologie de Senecio inaequidens. Ix ${ }^{\mathrm{ème}}$ Colloque International surla Biologie des Mauvaises Herbes. Dijon France. $1992 ; 65-72$

4. Ernst WHO. Invasion, dispersal and ecology of the south african neophyte Senecio inaequidens in The Netherlands: fron wool alien to railway and road alien. Acta Bot Neerl. 1998;47(1):131-151. 
5. Ahmed M, DA Wardle. Allelopathic potential of vegetative and flowering ragwort (Senecio jacobaea L.) plants against associated pasture species. Plant and Soil. 1994;164:61-68.

6. Barrero AF, EJMR Alvarez, RMR Alvarez. Alcaloides pirrolizidinicos de Senecio nebrodensis L. Anales de quimica. 1991;87(3):386-390.

7. Brown MS, RJ Molyneux. Effects of water and mineral nutrien deficiencies on pyrrolizidine alkaloid content of Senecio vulgaris flowers. J Sci Food Agric. 1996;70:209-211.

8. Krebs HCH, T Carl, GG Habermehl. Pyrrolizidine alkaloid composition in six Brazilian Senecio species. Phytochemistry. 1996; 43(6):1227-1229.

9. Vrieling K, H Devos. AM Vanwijk. Genetic analysis of the concentrations of pyrrolizidine alkaloids in Senecio jacobaea L. Phytochemistry. 1993;32(5):1141-1144

10. Hartmann T. XXIII Senecio spp. Biochemistry of the formulation of pyrrozilidine alkaloids in root culture. Biotechnology in Agriculture and Forestry. 1994;26:339-355.

11. Graser G, T Hartmann. Biosynthesis of spermidine, a direct precursor of pyrrolizidine alkaloids in root cultures of Senecio vulgaris L. Planta. 2000;211:239-245.
12. Wardle DA, KS Nicholson, A Rahman. Influence of plant age on the allelopathic potential of nodding thistle (Carduus nutans L.) Against pasture grasses and legumes. Weed Research. 1993;33:69-78.

13. Wardle DA, KS Nicholson, A Rahman. Ecological effects of the invasive weed species Senecio jacobaea L. (Ragwort) in a New Zeland pasture. Agriculture Ecosystems \& Environment. 1995;56:19-28.

14. Bai Y, W Majak. Pyrrozilidine alkaloids of three species of Senecio in British Columbia. Planta Med. 1996;62:71-72.

15. Perez CAL, A Arciniegas, A Castro, et al. Pyrrolizidine alkaloids from Senecio roseus and Senecio helodes. J Nat Prod. 1997; 60:1322-1325.

16. Inderjit M, Dakshini KM. On laboratory bioassay in allelopathy. The Botanical Review. 1995;61(1):28-44.

17. Inderjit, KI Keating. Allelopathy: Principles, procedures, processes, and promises for biological control. Advances in Agronomy. 1999;67:141230 .

18. Hoagland DR, DI Arnon. The water-culture method for growing plants without soil. Calif Agric Exp Stn Manual. 1950;347:32. 